\title{
Modelling the mechanical effects of tracheal tubes in normal subjects
}

\author{
P.R.M. Rocco, W.A. Zin
}

Modelling the mechanical effects of tracheal tubes in normal subjects. P.R.M. Rocco, W.A. Zin. @ERS Journals Ltd 1995.

ABSTRACT: The addition of tracheal tubes to the respiratory system contributes an extra mechanical burden in terms of pressure necessary to overcome its own resistance.

On the basis of experimental data from the literature and on a previously reported mathematical model of the inspirogram, we wished to study predictions of pressures, volume, flow and work of breathing during the use of tracheal tubes.

The present investigation indicates that: 1) the loss in volume is greater at the beginning of inspiration and with narrower tubes; 2) in order to preserve tidal volume the inspiratory drive must be increased at any time during inspiration with the use of diminishing internal diameter of the tubes; 3) alternatively, tidal volume can be maintained by increasing inspiratory duration; and 4) the addition of tubes with internal diameter of $9 \mathrm{~mm}($ no. 9) and $8 \mathrm{~mm}($ no. 8) increases the total resistive work by 115 and $154 \%$, respectively, whilst total elastic work decreases 9 and $16 \%$ in relation to the nonintubated patient.

These findings are consequent to the turbulent flow pattern that normally occurs within the tracheal tubes and connectors themselves. We believe they are relevant to the physician confronted with a patient needing tracheal intubation.

Eur Respir J., 1995, 8, 121-126.
Laboratory of Respiration Physiology, Carlos Chagas Filho Biophysics Institute, Federal University of Rio de Janeiro, Ilha do Fundão, Rio de Janeiro, Brazil.

\section{Correspondence: W.A. Zin}

Universidade Federal do Rio de Janeiro Instituto de Biofísica Carlos Chagas Filho Centro de Ciências de Saúde - G2-042

Ilha do Fundão

21949-900 - Rio de Janeiro - RJ

Brazil

\section{Keywords: Control of breathing} intensity of respiratory driving pressure mathematical modelling respiratory mechanics

tracheal tubes

work of breathing

Received: February 171994

Accepted after revision September 101994

Supported by Financing for Studies and Projects (FINEP) and National Council for Scientific and Technological Development (CNPq), Brazil.
The addition of tracheal tubes to the airways contributes an extra mechanical burden to the respiratory system (rs) [1-5]. Their resistance is highly flow-dependent, augmenting disproportionately with increasing flow rates [6-8]. Only a few studies have dealt with the mechanical effects on the respiratory system (other than the increased resistive work of breathing) originating from the use of tracheal tubes $[8,9]$. Probably, the scanty data on respiratory mechanical effects of intubation could be ascribed to the complex and sometimes dangerous experiments that would have to be performed in human beings. In order to avoid these difficulties, mathematical and mechanical models of the intubated respiratory system are very useful. Unfortunately, in general, other accepted models that employ actual human data do not deal with intubation [10-12], and those that take into account tracheal tubes do not address the human respiratory system $[1,2,5$, 13].

In the present investigation, a model originally proposed and validated by ZIN and co-workers [14-18] has been used. They presented model predictions of the immediate (first loaded breath) response to inspiratory resistive loading, based on inspiratory driving pressure waves and on active respiratory mechanics data $[15,17]$. Their model predictions were compared with experimental results and closely fitted the latter.

Hence, the aims of the present study are threefold. Firstly, using real human mechanical data, we wanted to calculate the time profiles of driving pressure, volume and flow throughout inspiration for control driving pressure, and also when driving pressure is increased, thus simulating commonly found pathophysiological situations. From these data respiratory system elastic, intrinsic resistive, tracheal tube resistive, and total resistive pressures, and respiratory system elastic, tracheal tube resistive and total resistive work of breathing are calculated. Secondly, we wanted to compute the loss in volume secondary to the addition of tracheal tubes to the respiratory system. Thirdly, we wanted to calculate the increases in respiratory driving pressure and inspiratory duration $\left(\mathrm{TI}_{\mathrm{I}}\right)$ necessary to maintain tidal volume (VT). We believe such a comprehensive analysis of the effects of tracheal tubes on the human respiratory system has not hitherto been performed. 


\section{Material and methods}

\section{Model definition}

In making numerical predictions of inspiratory parameters it is necessary: 1) to define the inspiratory driving pressure waveform; 2) to characterize the impedance offered by the respiratory system; 3 ) to describe the equation of motion of the active respiratory system; and 4) to reevaluate it with the tracheal tubes added.

\section{Driving pressure}

Pressure developed at the airway opening during an inspiratory effort against occluded airways at relaxed volume $(\mathrm{Vr})$ of the respiratory system $\left(\mathrm{P}^{\circ} \mathrm{ao}\right)$ allows quantification of the neuromuscular inspiratory drive potentially available to produce breathing movements [19, 20]. In anaesthetized subjects the occlusion pressure wave was [17]:

$$
\mathrm{P}^{\circ} \mathrm{ao}(\mathrm{t})=16.5 \mathrm{t}^{4}-44.3 \mathrm{t}^{3}+3.3 \mathrm{t}^{2}+5.8 \mathrm{t}
$$

where $t$ is time (in seconds) from the onset of the occluded effort.

\section{Active impedance}

In the same subjects from whom $\mathrm{P}^{\circ} \mathrm{ao}(\mathrm{t})$ was obtained, average active elastance of the respiratory system (E'rs) and intrinsic resistance of the respiratory system (R'rs) amounted to, $31.2 \mathrm{cmH}_{2} \mathrm{O} \cdot l^{-1}$ and $2.15 \mathrm{cmH}_{2} \mathrm{O} \cdot l^{-1} \cdot \mathrm{s}$, respectively [21].

\section{Equation of motion}

The equation of motion of the respiratory system can be adequately represented by a single first-order differential equation:

$$
\mathrm{P}^{\circ} \mathrm{ao}(\mathrm{t})=\mathrm{E}^{\prime} \mathrm{rs} \cdot \mathrm{V}(\mathrm{t})+\mathrm{R}^{\prime} \mathrm{rs} \cdot \dot{\mathrm{V}}(\mathrm{t})
$$

where at any instant $(\mathrm{t}), \mathrm{P}^{\circ}$ ao generates instantaneous flow (V) and volume (V) displacement from Vr. During quiet breathing, inertial forces are negligible [22].

The present model predictions in nonintubated subjects were made using equation (2), and assuming that R'rs and E'rs did not vary within the range of volumes and flows calculated.

\section{Addition of tracheal tubes}

The pressure-flow relationships of the three tracheal tubes $(8.0,8.5$ and $9 \mathrm{~mm}$ ID) can be described by Rohrer's equation $\left(\mathrm{P}=\mathrm{K}_{1} \cdot \dot{\mathrm{V}}+\mathrm{K}_{2} \dot{\mathrm{V}}^{2}\right)$. Rohrer's constants $\left(\mathrm{K}_{1}\right.$ and $\mathrm{K}_{2}$ ) pertaining to the two tracheal tubes used in the present model were provided previously [21]. Under these circumstances, the model predictions were based on:

$$
\mathrm{P}^{\circ} \mathrm{ao}(\mathrm{t})=\mathrm{E}^{\prime} \mathrm{rs} \cdot \mathrm{V}(\mathrm{t})+\left(\mathrm{R}^{\prime} \mathrm{rs}+\mathrm{K}_{1}\right) \cdot \dot{\mathrm{V}}(\mathrm{t})+\mathrm{K}_{2} \dot{\mathrm{V}}^{2}(\mathrm{t})
$$

In this model, it has been assumed that tracheal tubes do not affect the intensity (rate of rise) and shape of inspiratory neural drive.

\section{Limitations}

The present results apply to the first loaded breath in anaesthetized humans. Naturally, in pathophysiological situations the $\mathrm{P}^{\circ} \mathrm{ao}(\mathrm{t})$ waveform and the timing of breathing could change, thus modifying the equations and parameters in the model. Notably, under steady-state conditions resistive loading may generate dynamic hyperinflation and, hence, intrinsic positive end-expiratory pressure (PEEPi); thus, equation (1) would become: $P(t)=E \cdot V(t)+R \cdot V(t)$ + PEEPi. Nevertheless, the data gathered from this theoretical study can shed some light on otherwise unknown aspects of respiratory behaviour in the presence of added loads.

\section{Data production}

Using the model, $\mathrm{P}(\mathrm{t}), \mathrm{V}(\mathrm{t})$, and $\mathrm{V}(\mathrm{t})$ were calculated at $1 \mathrm{~ms}$ intervals by means of the iterative computational procedure used previously [11, 15-18]. These functions allow the computation of elastic pressure (Pel,rs $(\mathrm{t})$ $\left.=\mathrm{E}^{\prime} \mathrm{rs} \cdot \mathrm{V}(\mathrm{t})\right)$, intrinsic respiratory system resistive pressure $\left(\operatorname{Pres}, r s(t)=R^{\prime} r s \cdot V(t)\right)$, tracheal tube resistive pressure $\left(\operatorname{Pres}, \mathrm{t}(\mathrm{t})=\mathrm{K}_{1} \dot{\mathrm{V}}(\mathrm{t})+\mathrm{K}_{2} \dot{\mathrm{V}}^{2}(\mathrm{t})\right)$, total resistive pressure $(\operatorname{Pres}, \operatorname{tot}(\mathrm{t})=\operatorname{Pres}, \mathrm{rs}(\mathrm{t})+\operatorname{Pres}, \mathrm{t}(\mathrm{t}))$, respiratory system elastic work $(\mathrm{Wel}, \mathrm{rs}(\mathrm{t})=\Sigma(\operatorname{Pel}, \mathrm{rs}(\mathrm{t}) \cdot \Delta \mathrm{V}(\mathrm{t})))($ where $\Delta \mathrm{V}$ is the difference between two consecutive volume points), tracheal tube resistive work $($ Wres, $t(t)=\Sigma(\operatorname{Pres}, t(t) \cdot \Delta \mathrm{V}$ $(\mathrm{t})))$, total resistive work $($ Wres, $\operatorname{tot}(\mathrm{t})=\Sigma(\operatorname{Pres}, \operatorname{tot}(\mathrm{t}) \cdot \Delta \mathrm{V}(\mathrm{t})))$ and total work $(\mathrm{Wtot}(\mathrm{t})=\mathrm{Wres}$, tot $(\mathrm{t})+\mathrm{Wel}, \mathrm{rs}(\mathrm{t}))$ throughout inspiratory duration $(1.2 \mathrm{~s})$. In addition, the variables were also calculated for doubled (2P) and quadrupled (4P) values of $\mathrm{P}^{\circ} \mathrm{ao}(\mathrm{t})(\mathrm{P})$.

\section{Results}

The time courses of $\mathrm{V}$ throughout inspiration are depicted in figure 1 . It can be seen that with the addition of tracheal tubes $\mathrm{V}(\mathrm{t})$ decreases progressively, the loss in $\mathrm{V}$ being proportionately greater early in inspiration. Indeed, at end-inspiration the three curves converge. In figures $1 \mathrm{~b}$ and $\mathrm{c}, \mathrm{P}^{\circ} \mathrm{ao}(\mathrm{t})$ is doubled and quadrupled, respectively. Qualitatively, the same pattern found in figure 1a can be observed.

In figure 2 , losses in volume caused by tube no. 9 at the beginning of inspiration $(\mathrm{t}=0.05 \mathrm{~s})$ amount to 33.2, 37.3 and $43.9 \%$ when $\mathrm{P}, 2 \mathrm{P}$ and $4 \mathrm{P}$ were used, respectively. For tube no. 8 the corresponding values are 43 , 47 , and $52.5 \%$. At $\mathrm{T}$, $4.2,7.9$, and $15.8 \%$ of $\mathrm{V}_{\mathrm{T}}$ are lost when tube no. 9 is used ( $\mathrm{P}, 2 \mathrm{P}$ and $4 \mathrm{P}$, respectively), 

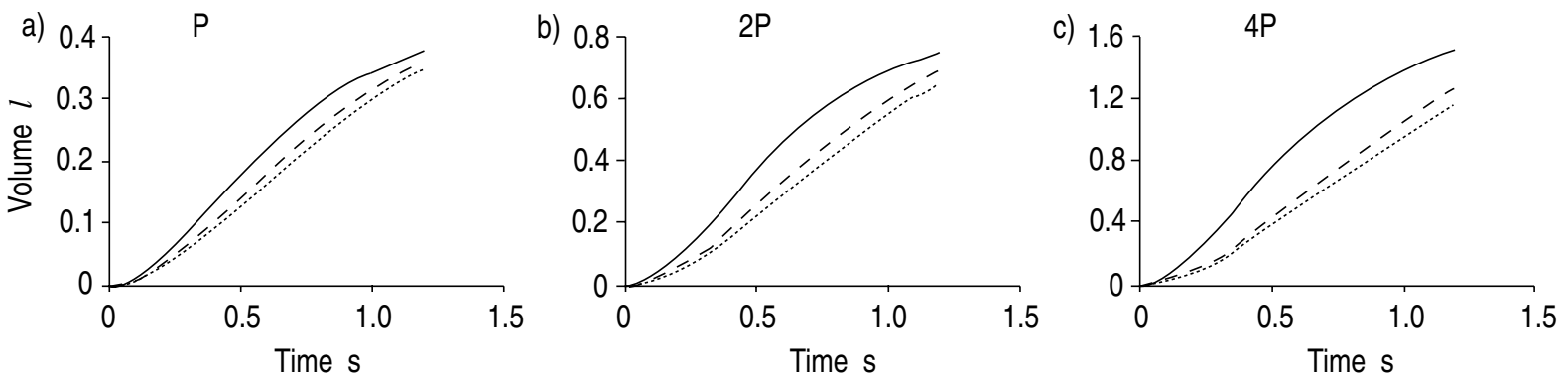

Fig. 1. - Volume plotted against time during inspiration. In the panels each line represents time course of volume for: —— : total resistance (R) equals lower active intrinsic respiratory system resistance ( $\mathrm{R}$ 'rs); - - : : R equals R'rs plus the addition of the resistance pertaining to tube no. 9 (plus equipment); …….. : R equals R'rs plus the addition of the resistance pertaining to tube no. 8 (plus equipment). a) average control driving pressure was used in computations $(\mathrm{P})$; b) driving pressure was doubled $(2 \mathrm{P})$; c) driving pressure was quadrupled (4P). Note that ordinate scale is expanded two fold from a to b, and four fold from a to $\mathrm{c}$. For the sake of clarity the curves pertaining to tube no. 8.5 are not shown, but they lay between those of tubes no. 9 and no. 8 .

and tube no. 8 yields VT losses of $7.2,13.1$, and $23 \%$, respectively.

The amount of change in inspiratory drive required to compensate the $\mathrm{V}(\mathrm{t})$ losses shown in figure 2 is obtained as the percentage ratio of control $\mathrm{V}(\mathrm{t})$ to $\mathrm{V}(\mathrm{t})$ found with added tracheal tubes [15] (fig. 3). At $t=0.05 \mathrm{~s}$, the required increases in inspiratory drive caused by tube no. 9 amount to $50.3,60.6$, and $78.2 \%$ when $\mathrm{P}, 2 \mathrm{P}$, and $4 \mathrm{P}$ were used, respectively; and for tube no. 8 the corresponding values are $73.8,88.5$, and $110.2 \%$. At $\mathrm{TI}_{\mathrm{I}}$, the corresponding values are $4.4,8.6$, and $18.8 \%$ when tube no. 9 was used; and $7.7,14.1$, and $29.9 \%$ for tube no. 8 .

Tidal volume can also be maintained by increasing TI. For tube no. 9 Ti should increase $0.07,0.12$, and $0.23 \mathrm{~s}$ when driving pressure equals $\mathrm{P}, 2 \mathrm{P}$, and $4 \mathrm{P}$, respectively. For tube no. 8 the corresponding values are $0.14,0.19$, and $0.32 \mathrm{~s}$.

The addition of tracheal tubes also modifies the distribution of pressures within the system. In figure $4 \mathrm{a}$, at the beginning of inspiration Pres,rs is greater than Pel,rs; as inspiration continues, Pres,rs decreases and Pel,rs increases. In figures $4 \mathrm{~b}$ and $\mathrm{c}$, Pres,rs, Pel,rs and Pres,t are plotted (as percentage of total driving pressure) against time throughout inspiration for tubes no. 9 and no. 8, respectively. Due to the presence of Pres,t at the onset of inspiration, Pel,rs and Pres,rs decrease similarly (33.2 and $33.6 \%$ (tube no. 9), and 42.9 and $42.8 \%$ (tube no. $8)$, respectively). At the end of inspiration, Pel,rs decreases
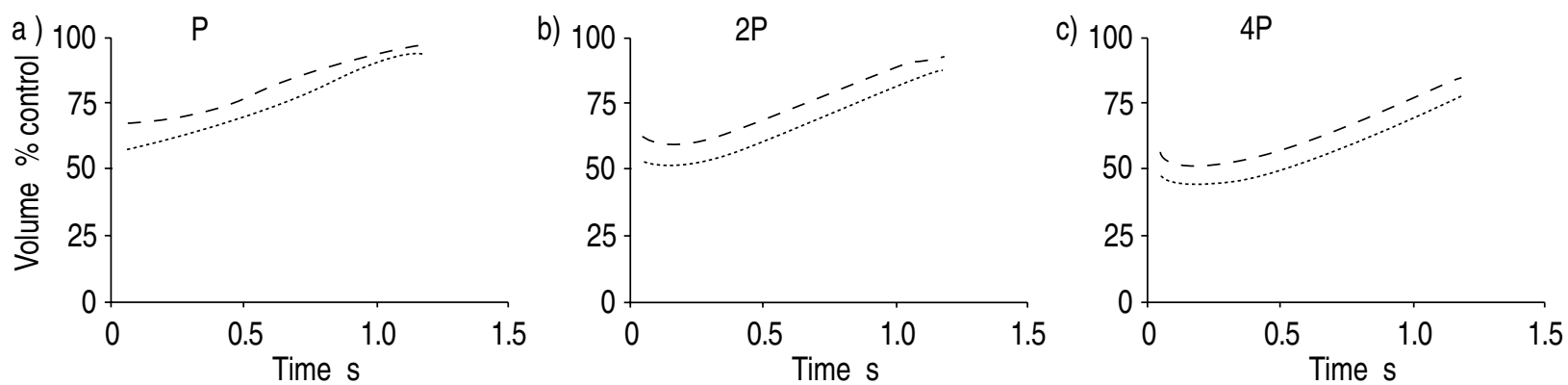

Fig. 2. - Inspired volume, expressed as percentage of control value, i.e. without tracheal tube $(\mathrm{V}(\mathrm{t})(\%$ control $)=\mathrm{V}(\mathrm{t})($ with tracheal tube $) / \mathrm{V}(\mathrm{t})$ (control)), plotted against time during inspiration. Lines indicate the addition of tracheal tubes: - - - no. 9 (plus equipment); ........: no. 8 (plus equipment). a) average control driving pressure was used in computations (P); b) driving pressure was doubled (2P); c) driving pressure was quadrupled (4P).
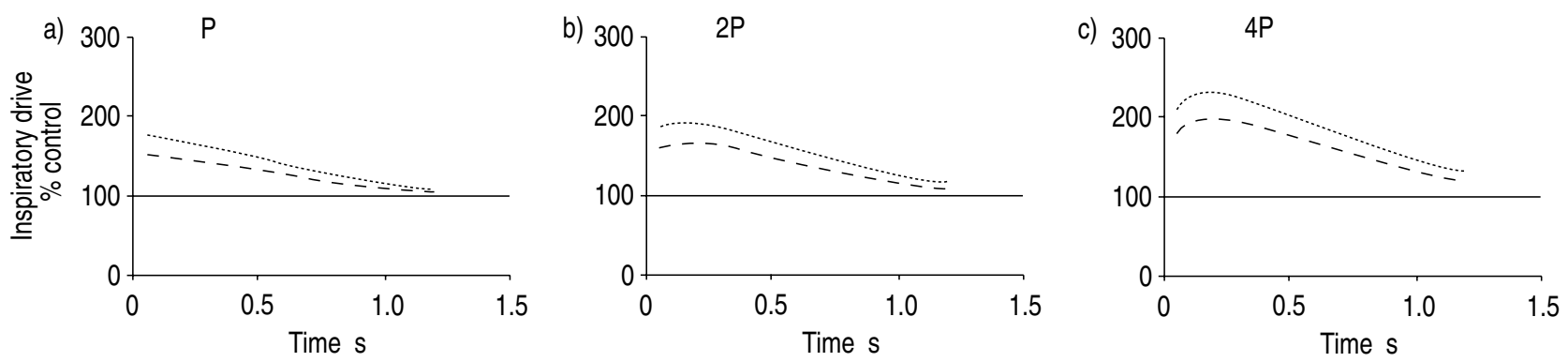

Fig. 3. - Changes in intensity of inspiratory drive, expressed as percentage control (without tracheal tube), required to maintain tidal volume constant in the face of added tracheal tubes (no. 8 and no. 9) plotted against time during inspiration. a) average control driving pressure was used in computations $(\mathrm{P}) ;$ b) driving pressure was doubled $(2 \mathrm{P})$; c) driving pressure was quadrupled $(4 \mathrm{P})$. - - - tube no. $9 ; \quad \cdots \cdots . . .$. : tube no. 8 . 
a)

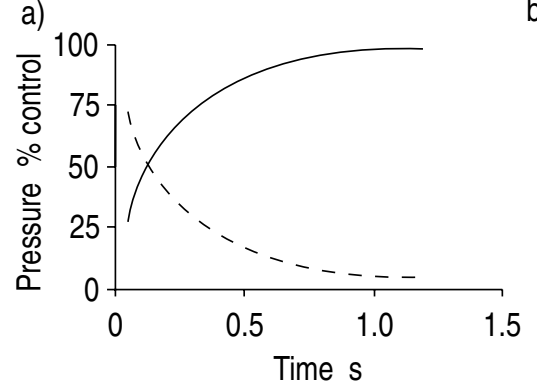

b)

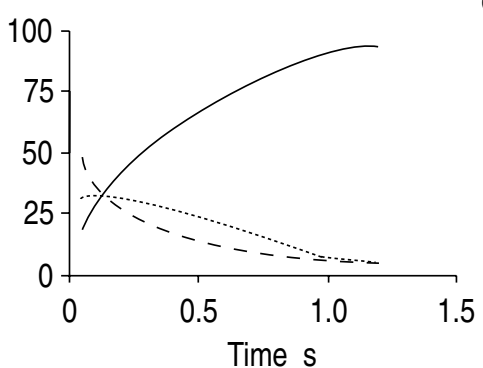

c)

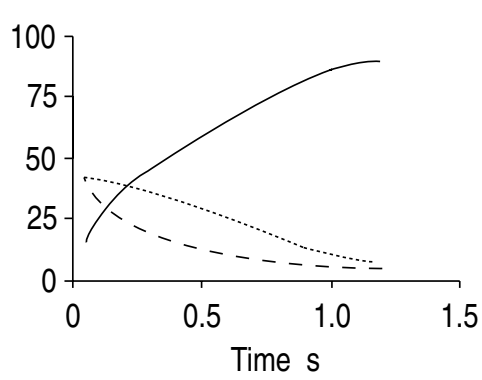

Fig. 4. - Pressure, expressed as percentage of control driving pressure, plotted against time during inspiration. a) total resistance (R) equals lower active intrinsic respiratory system resistance (R'rs); b) R equals R'rs plus resistance pertaining to tube no. 9 (plus equipment); c) R equals R'rs plus resistance pertaining to tube no. 8 (plus equipment). _—_ respiratory system elastic pressure (Pel, rs); - - - : intrinsic respiratory system resistive pressure (Pres,rs); ……... : tracheal tube resistive pressure (Pres,t).
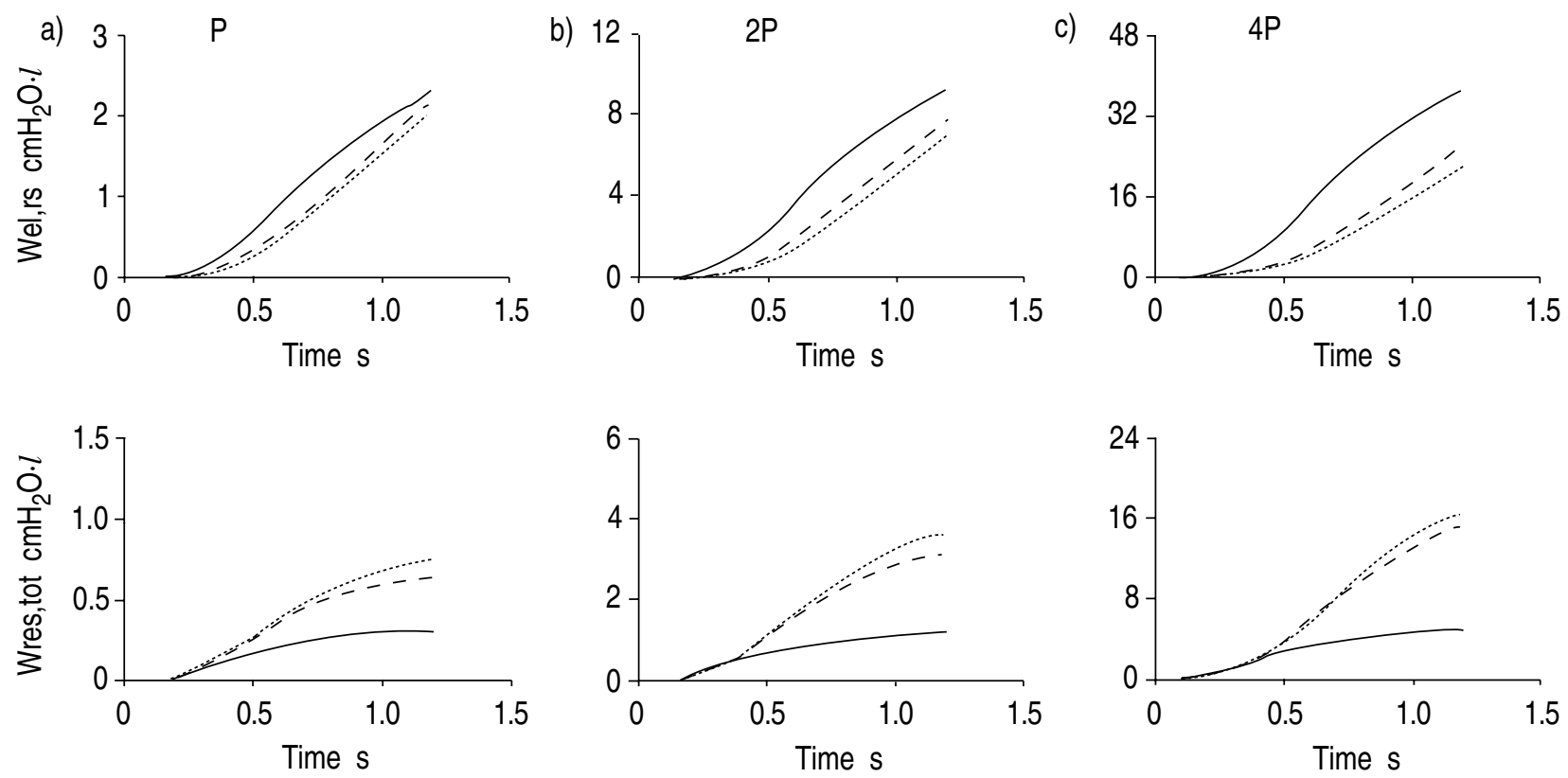

Fig. 5. - Respiratory system elastic work (Wel,rs upper trace) and total resistive work (Wres,tot lower trace) plotted against time during inspiration. …..... : total resistance $(\mathrm{R})$ equals lower active intrinsic respiratory system resistance (R'rs) plus resistance pertaining to tube no. 8 and equipment; $---: \mathrm{R}$ equals $\mathrm{R}$ 'rs plus resistance relative to tube no. 9 and equipment; — - : R=R'rs. a) average control driving pressure was used in the computations $(\mathrm{P})$; b) driving pressure was doubled (2P); c) driving pressure was quadrupled (4P). Note that ordinate scale is expanded fourfold from a to $b$, and 16 fold from a to $c$.

less than at its beginning (4.8 and $8.0 \%$ for tubes no. 9 and no.8, respectively). However, Pres,rs increases slightly (3.3 and $10.1 \%$ for tubes no. 9 and no. 8 , respectively).

Figure 5 shows that the addition of tube no. 9 increases Wres,tot at TI by 115,162 and $215 \%$, in relation to the control conditions (without tracheal tubes) when $\mathrm{P}, 2 \mathrm{P}$, and $4 \mathrm{P}$ were used, respectively. For tube no. 8, the corresponding values are 154, 201, and $243 \%$. Wel,rs decreases 9, 18 and $41 \%$ (tube no. 9) when P, 2P and $4 \mathrm{P}$ were used, respectively; for tube no. 8 the corresponding values were 16,32 and $72 \%$.

\section{Discussion}

The addition of tracheal tubes to respiratory system decreases $\mathrm{V}(\mathrm{t})$ progressively (fig. 1). The loss in $\mathrm{V}$ is proportionately greater early in inspiration, and at endinspiration the three curves converge rather. This reflects decreased rate of rise of $\mathrm{P}^{\circ}$ ao with a consequent decrease in flow. In fact, because of the curvilinear pressure-flow relationships of the tracheal tubes, a greater amount of pressure is spent against the turbulent component of flow-resistance at higher flows. In the present study, these flows occur early in inspiration $(0.4 \mathrm{~s}$ under control conditions and $0.55-0.6 \mathrm{~s}$ in the presence of tracheal tubes); hence, the widest gap between the inspirograms, generated with or without tubes, occur at those times during inspiration. In relation to the control drive, with increased $\mathrm{P}^{\circ}$ ao the tubes cause a greater loss in volume, both in absolute terms and relative to the inspirograms for $\mathrm{R}=\mathrm{R}$ 'rs. Again, this phenomenon is due to the curvilinear pressure-flow relationships of the tubes resulting in larger Pres,t losses with increased inspiratory flow. These data are in agreement with the results obtained by ZIN and co-workers [17] in anaesthetized humans. GAL [3] demonstrated that in awake, healthy, intubated individuals slow vital capacity was unchanged, but forced vital capacity (FVC) decreased significantly to $89 \%$ of control. 
In addition, Colgan et al. [9] reported that in the presence of tubes $7.5-8.5 \mathrm{~V}_{\mathrm{T}}$ falls $5.6 \%$ after extubation, a change in volume in the same order of magnitude as those presently reported (fig. 2).

In order to maintain $\mathrm{V}(\mathrm{t})$, the inspiratory drive must be increased with the use of tracheal tubes, and, additionally, with diminishing internal diameter of the tubes (fig. 3). Alternatively, VT could also be maintained by increasing $T_{I}$ in the face of added tracheal tubes $[14,23]$. Our study is the first to report this mechanism of $\mathrm{V}_{\mathrm{T}}$ compensation against added tracheal tubes. However, unless expiratory duration decreased by the same amount, the increase in TI would represent a drop in ventilation [24]. It should be noted that these predictions are based on the assumption that $\mathrm{P}^{\circ}$ ao could be expressed by equation (1) beyond $\mathrm{T} \mathrm{I}=1.2 \mathrm{~s}$.

It can be seen in figure 4 that due to the presence of Pres,t, at the onset of inspiration, Pel,rs and Pres,rs decrease similarly. At the end of inspiration, Pel,rs decreases less than at the beginning, and Pres,rs increases slightly. These results are, in part, due to the increased resistance, which induces a larger lag between driving pressure and attained volume [14, 15, 17]. In other words, if TI were allowed to increase, Pres,rs and Pel,rs would eventually reach their control values. In this connection, in figure 1 it can be seen that the addition of progressively narrower tracheal tubes leads to smaller inspired volumes with identical total driving pressures. In addition, the larger Pres, $t$ at the beginning of inspiration can be ascribed to a higher rate of rise of driving pressure at these moments, with a consequent higher flow [17]. Summarizing, the energy dissipated to overcome Pres,t is related to decreases in Pel,rs and Pres,rs at the first moments of inspiration, whereas at $\mathrm{T}_{\mathrm{I}}$ it is strongly related to a decrease in Pel,rs.

Figure 5 shows that Wres,tot increases when tracheal tubes are used, and, furthermore, the smaller the tube diameter the larger is Wres,tot, in accordance with previous reports $[1,2,4,7,13,25]$. For $\mathrm{R}=\mathrm{R}$ 'rs, when $\mathrm{P}^{\circ}$ ao is doubled and quadrupled (fig. $5 \mathrm{~b}$ and c, respectively) Wres, tot shows an increase proportional to those in $\mathrm{P}^{\circ}$ ao and $\mathrm{V}$, i.e. for $2 \mathrm{P}$, Wres, tot quadruples (since both $\mathrm{P}$ and $\mathrm{V}$ are doubled), and for $4 \mathrm{P}$, Wres, tot shows values that are 16 fold those during control condition. However, this is not the case when tracheal tubes are employed; as can be noted in that Wres,tot with tubes is greater than the values expected by simply doubling and quadrupling driving pressure (fig. $5 \mathrm{~b}$ and c). Again, the turbulent flow pattern generated within the tubes could be responsible for this behaviour. Consequently, V(t) diminishes, yielding a decrease in Wel,rs. Our values of Wel,rs and Wres,tot are in agreement with previous studies on spontaneously breathing anaesthetized subjects maintaining similar $\mathrm{V}_{\mathrm{T}}$ and frequency $(f)[2,25]$.

More recently, BOLDER et al. [2] and FIASTRO et al. [13], using mechanical models to simulate spontaneous breathing through different tracheal tubes, showed that Wres,t increases progressively with narrower tracheal tubes and with increasing minute ventilation (VE). FIASTRO et al. [13] reported that a decrease in tube diameter from no. 9 to no. 8 yields an increase of $42.9 \%$ in Wres,t,
$\mathrm{VT}_{\mathrm{T}}(0.5 l)$ and $f\left(15\right.$ breaths $\left.\cdot \mathrm{min}^{-1}\right)$ being constant. According to Bolder et al. [2], ( $\mathrm{VT}_{\mathrm{T}}=0.35 \mathrm{l}$ and $f=20$ breaths $\left.\cdot \mathrm{min}^{-1}\right)$, when the tube diameter is reduced from no. 9.0 to no. 8.0, Wres,t increases $41.9 \%$. Our results indicate that when tracheal tubes are changed from no. 9 to no. 8 Wres,t will increase $35.9 \%,\left(\mathrm{~V}_{\mathrm{T}}=0.35 l\right.$ and $f=17.9$ breaths. $\left.\mathrm{min}^{-1}\right)$. In this context, BOLDER et al. [2] demonstrated that the higher the VE the larger is the difference in Wres,t between tubes.

BOLDER et al. [2] also reported that for tube no. 8, Wres, $\mathrm{t}$ is $0.43 \mathrm{cmH}_{2} \mathrm{O} \cdot l$ at $\mathrm{VE}=4.2 l \cdot \mathrm{min}^{-1}$ and $f=12$ beats $\cdot \mathrm{min}^{-1}$, and it corresponds to $0.85 \mathrm{cmH}_{2} \mathrm{O} \cdot l$ when $\mathrm{VE}_{\mathrm{E}}=7.0 \mathrm{l} \cdot \mathrm{min}^{-1}$ and $f=20$ breaths $\cdot \mathrm{min}^{-1}$. For the same tube, the present results show a value of $0.50 \mathrm{cmH}_{2} \mathrm{O} \cdot \mathrm{l}$ at $\mathrm{V}_{\mathrm{E}}=6.25 l \cdot \mathrm{min}^{-1}\left(\mathrm{~V}_{\mathrm{T}}\right.$ of $0.35 l, f$ of $\left.17.9 \mathrm{breaths} \cdot \mathrm{min}^{-1}\right)$, which is intermediate between the data reported by BOLDER et al. [2]. Hence, the aforementioned findings further support the validity of our model.

In the present computational analysis the von EulerCauchy method for "initial value" differential equation was used [26]. We computed $\mathrm{P}, \mathrm{V}$ and $\mathrm{V}$ at $1 \mathrm{~ms}$ intervals, and for each value of $t$ (any time during inspiration) three iterations were performed. The option for three in opposition to four or more iterations accounted for a reduction in computational time. Furthermore, at any $\mathrm{t}, \mathrm{V}$ increased only $0.01 \%$ from the third to the fourth passage, and $6 \times 10^{-5} \%$ from the fourth to the fifth.

In the present computations, a model previously developed and reported to be correct was used [14-18, 27]. In agreement with studies on humans anaesthetized with methoxyflurane $[19,20]$ the occluded Ti (infinite load) measured by BeHRAKIS et al. [21] was similar to the unoccluded one. Based on this finding, in all instances $\mathrm{TI}_{\mathrm{I}}$ in the present model was limited to the average control TI (1.2 s) [17]. Furthermore, it has been shown in man that the shape of the driving pressure does not depend on the level of inspiratory effort [19]. Since $\mathrm{P}^{\circ}$ ao has been shown to represent the inspiratory driving pressure during control conditions and to remain unaltered during the first loaded breath (see [17] for references), it has been used in our computations. On the basis of the aforementioned premises, the results discussed here pertain to the first loaded breath in spontaneously breathing humans (i.e. before a reflex change in $\mathrm{P}^{\circ}$ ao occurs).

The present results indicate that: 1) in relation to the nonintubated condition, the loss in volume is greater early in inspiration, with increasing pressure, and in the presence of narrower tubes; 2) at any time during inspiration, the inspiratory drive must be increased with the use of tracheal tubes and will be greater with the diminishing internal diameter of the tubes; 3 ) the energy dissipated to overcome the tracheal tube resistance is related to a decrease in Pel,rs and Pres,rs at the first moments of inspiration, whereas at TI equal to $1.2 \mathrm{~s}$ it is strongly related to a decrease in Pel,rs; 4) Wres,tot increases proportionately to augmented pressure (2P and $4 \mathrm{P}$ ) when respiratory system alone is taken into account in the calculations, and it is greater when tracheal tubes are included; and 5) these findings are consequent to the turbulent flow pattern that normally occurs within the tracheal tubes themselves. 
Finally, we believe that these results should be instructive for enlightening the physician dealing with a patient needing tracheal intubation. After intubation, the patient himself will necessarily increase his respiratory drive, or the mechanical ventilator setting will need special care in order to provide adequate minute ventilation. In addition, it should be stressed that the behaviour of a tracheal tube placed in the patient may be different from the theoretical behaviour as a result of secretions, head or neck position, and tube deformation [28].

Acknowledgements: The authors wish to express their gratitude to A.C. de Souza Quaresma for his technical assistance. They are also grateful to IBM Brazil for kindly donating the PC-AT microcomputer used in the data analysis.

\section{References}

1. Bersten AD, Rutten AJ, Vedig AE, Skowronski GA Additional work of breathing imposed by endotracheal tubes, breathing circuits, and intensive care ventilators. Crit Care Med 1989; 17: 671-677.

2. Bolder PM, Healy TEJ, Bolder AR, Beatty PCW, Kay B. The extra work of breathing through adult endotracheal tubes. Anesth Analg 1986; 65: 853-859.

3. Gal TJ. Pulmonary mechanics in normal subjects following endotracheal intubation. Anesthesiology 1980; 52: 2735 .

4. Shapiro M, Wilson RK, Casar G, Bloom K, Teague RB Work of breathing through different sized endotracheal tubes. Crit Care Med 1986; 14: 1028-1031.

5. Wall WA. Infant endotracheal tube resistance: effects of changing length, diameter and gas density. Crit Care Med 1980; 8: 38-40.

6. Ferris Jr BC, Mead J, Opie LH. Partitioning of respiratory flow resistance in man. J Appl Physiol 1964; 19: 653-658.

7. Habib MP. Physiologic implications of artificial airways. Chest 1989; 96: 180-184.

8. Sullivan M, Palliota J, Saklad M. Endotracheal tube as a factor in measurement of respiratory mechanics. J Appl Physiol 1976; 41: 590-592.

9. Colgan FJ, Liang JQ, Barrow RE. Noninvasive assessment by capacitance respirometry of respiration before and after extubation. Anesth Analg 1975; 54: 807-813.

10. Younes M, Riddle W, Polacheck J. A model for the relation between respiratory neural and mechanical outputs. III. Validation. J Appl Physiol: Respirat Environ Exercise Physiol 1981; 51: 990-1001.

11. Riddle W, Younes M. A model for the relation between respiratory neural and mechanical outputs. II. Methods. J Appl Physiol: Respirat Environ Exercise Physiol 1981; 51: 979-989.

12. Younes M, Riddle W. A model for the relation between respiratory neural and mechanical outputs. I. Theory. J Appl Physiol: Respirat Environ Exercise Physiol 1981; 51: 963-978.
13. Fiastro JF, Habib MP, Quan SF. Pressure support compensation for inspiratory work due to endotracheal tubes and demand continuous positive airway pressure. Chest 1988; 93: 499-505.

14. Milic-Emili J, Zin WA. Breathing responses to imposed mechanical loads. In: Cherniack NS, Widdicombe JG, eds. Handbook of Physiology. The Respiratory System. Control of Breathing. Bethesda, American Physiological Society, 1986; pp. 751-769.

15. Zin WA, Rossi A, Milic-Emili J. Model analysis of respiratory responses to inspiratory resistive loads. $J$ Appl Physiol: Respirat Environ Exercise Physiol 1983; 55: 1565-1573.

16. Zin WA, Rossi A, Zocchi L, Milic-Emili J. Model analysis of respiratory response to inspiratory elastic loads. J Appl Physiol: Respirat Environ Exercise Physiol 1984; 57: 271-277.

17. Zin WA, Behrakis PK, Luijendijk SCM, et al. Immediate response to resistive loading in anesthetized humans. $J$ Appl Physiol 1986; 60: 506-512.

18. Zin WA, Böddener A, Silva PRM, Pinto TMP, MilicEmili J. Active and passive respiratory mechanics in anesthetized dogs. J Appl Physiol 1986; 61: 1647-1655.

19. Derenne JP, Couture J, Iscoe S, Whitelaw WA, MilicEmili J. Occlusion pressures in men rebreathing $\mathrm{CO}_{2}$ under methoxyflurane anesthesia. J Appl Physiol 1976; 40: 805-814.

20. Whitelaw WA, Derenne JP, Milic-Emili J. Occlusion pressure as a measure of respiratory center output in conscious man. Respir Physiol 1975; 23: 181-189.

21. Behrakis PK, Higgs BD, Baydur A, Zin WA, Milic-Emili J. Active inspiratory impedance in halothane-anesthetized humans. J Appl Physiol: Respirat Environ Exercise Physiol 1983; 54: 1477-1481.

22. Ingram RH Jr, Pedley TJ. Pressure-flow relationships in the lungs. In: Macklem PT, Mead J, eds. Handbook of Physiology. The Respiratory System. Mechanics of Breathing. Bethesda, American Physiological Society, 1986; pp. 277-293.

23. Milic-Emili J. Loaded breathing. Bull Eur Physiopathol Respir 1984; 20: 429-431.

24. Grunstein MM, Wyazogrodski J, Milic-Emili J. Regulation of frequency and depth of breathing during expiratory threshold loading in cats. J Appl Physiol 1975; 38: 869-874.

25. Behrakis PK, Higgs BD, Baydur A, Zin WA, Milic-Emili J. Respiratory mechanics during halothane anesthesia and anesthesia-paralysis in humans. J Appl Physiol: Respirat Environ Exercise Physiol 1983; 55: 1085-1092.

26. Conte SD, DeBoor C. In: Elementary Numerical Analysis. An Algorithmic Approach. 2nd edn. New York, McGraw, 1972; pp. 233-240.

27. Zin WA, Pengelly LD, Milic-Emili J. Active impedance of respiratory system in anesthetized cats. J Appl Physiol: Respirat Environ Exercise Physiol 1982; 53: 149-157.

28. Wright PE, Marini JJ, Bernard GR. In vitro versus in vivo comparison of endotracheal tube airflow resistance. Am Rev Respir Dis 1989; 140: 10-16. 